\title{
¿Estar indizados o no? Esa es la cuestión
}

\author{
To Be Indexed or not to Be Indexed? That is the Question
}

\author{
Jorge Enrique Delgado Troncoso ${ }^{\text {a }}$ \\ Editor \\ ORCID: http://orcid.org/0000-0002-1127-9516 \\ Sandra Cecilia Delgado Troncoso \\ Asistente editorial
}

DOI: https://doi.org/10.11144/Javeriana.uo36-77.eion Redalyc: http://www.redalyc.org/articulo.oa? id $=231254499001$

Palabras clave: conocimiento científico, evaluación de revistas, índices bibliográficos, indización, revistas científicas, revistas odontológicas

Keywords: bibliographic indexes, dental journals, indexation, journal evaluation, scientific knowledge, scientific journals Áreas temáticas: odontología; cienciometría; epistemología; sociología de la ciencia

Thematic fields: dentistry; epistemology; scientometrics; sociology of science

El Departamento Administrativo de Ciencia, Tecnología e Innovación Colciencias, de Colombia, lanzó la más reciente convocatoria del Índice Bibliográfico Nacional Publindex para evaluar las revistas científicas arbitradas correspondientes a 2016. En esta oportunidad se utilizó una modificación de la anterior metodología que mantuvo la clasificación (A1, A2, B y C) y los criterios internacionales, aunque aumentó la exigencia en algunos ítems. Incluyó también una valoración predeterminante para inclusión de las revistas en los sistemas de información bibliográfica: el escalafón en otros sistemas. Ahora, para acceder a las categorías más altas A1 y A2, las revistas deben estar en los primeros dos cuartiles de índices citacionales como el Science Citation Index (SCI) y Scopus. Para las categorías B y C se requería que estuvieran en los cuartiles 3 y 4 de dichos sistemas. Para las dos últimas categorías se introdujo, además, una alternativa de medición: tener un índice H5 de Google Académico (Scholar), por encima de un estándar establecido por Colciencias. Todo el proceso fue muy confuso, la manera como se tomaron algunas decisiones no fue clara, como los $\mathrm{H} 5$ de referencia, y aparentemente se incumplieron algunos compromisos que Colciencias hizo con las instituciones que consideraron no presentarse a la evaluación. Como podía esperarse, hubo ganadores y perdedores.

En el caso de las revistas odontológicas, el resultado de esta evaluación dejó una situación bastante preocupante. De las siete revistas nacionales que formaban parte de Publindex (1) en la convocatoria anterior, CES Odontología, Revista Colombiana de Investigación Odontológica, Revista Nacional de Odontologia, Odontos, Ustasalud Odontologia, Universitas Odontologica y Revista de la Facultad de Odontología de la Universidad de Antioquia, solo la última quedó incluida en el índice de 2017. Ello deja a los autores colombianos que buscan revistas nacionales para divulgar conocimiento de relevancia nacional con una sola publicación que verá ahora aumentado su influjo de manuscritos y, posiblemente, se vea forzada a incrementar el porcentaje de trabajos rechazados. Por otro lado, los autores de la Universidad de Antioquia tendrán que buscar revistas del exterior para publicar.

Como se mostró en una publicación de 2014 (1), son contadas las revistas latinoamericanas incluidas en Scopus o el SCI. Los investigadores de las instituciones públicas serán los más afectados, así como de pronto los de instituciones privadas que usen a Publindex como referencia para valorar la productividad de sus académicos e investigadores. Del mismo modo, las revistas no indizadas se verán sustancialmente disminuidas si no habían implementado estrategias de posicionamiento internacional y

a Autor de correspondencia. Correo electrónico: jed41@pitt.edu 
mejoramiento de la gestión editorial. Este análisis no incluye muchas otras de las variables relacionadas con la generación y diseminación del conocimiento odontológico en Colombia. Un estudio más profundo incluiría, además, temas como solidaridad, equidad y confiabilidad para el avance de la investigación en el país, como lo menciona Mauricio Palacios de la revista Colombia Médica (2).

En esta situación, emergen de nuevo las preguntas que nosotros hemos formulado en otras ocasiones: ¿quién debe determinar la calidad de una revista científica? ¿Por qué seguir utilizando las citaciones como factor de calidad y escalafonamiento de las revistas? ¿Es esta potestad de los sistemas de información bibliográfica o los entes gubernamentales de ciencia, tecnología e innovación? ¿Cuál es el papel de las comunidades profesionales, académicas y científicas para determinar la validez, la calidad y la relevancia del conocimiento generado por la investigación? Entonces, ¿debemos buscar estar indizados o no?

\section{REFERENCIAS}

1. Delgado JE. Revistas científicas odontológicas de libre acceso en Iberoamérica y Colombia. Rev Fac Odontol Univ Antioq [internet]. 2014; 26(1): 126-51. Disponible en: https://www.scielo.org.co/scielo.php?script=sci_arttex t\&pid=S0121-246X2014000200009\&lng=en

2. Palacios M. La incertidumbre de las revistas científicas colombianas con Publindex. Colomb Med [internet]. 2017 oct-dic; 48(4). Disponible en: https://colombiamedica.univalle.edu.co/index.php/comedica/rt/printerFriendl y/3728/3457

Licencia Creative Commons CC BY 4.0

Cómo citar: Delgado JE, Delgado SC. ¿Estar indizados o no indizados?: Esa es la cuestión. Univ Odontol. 2017 jul-dic; 36(77). https://doi.org/10.11144/Javeriana.uo36-77.eion 